\title{
Factors Influencing Early Neurological Recovery in Patients with Acute Ischemic Stroke
}

\author{
Orapen SUKHAVULLI ${ }^{1, *}$, Siriorn SINDHU ${ }^{1}$, \\ Wanpen PINYOPASSAKUL ${ }^{1}$ and Chukiat VIWATWONGKASEM ${ }^{2}$ \\ ${ }^{I}$ Department of Surgery Nursing, Faculty of Nursing, Mahidol University, Nakhon Pathom 73170, Thailand \\ ${ }^{2}$ Department of Biostatistics, Faculty of Public Health, Mahidol University, Bangkok 10400, Thailand
}

('Corresponding author's e-mail: sorapen@wu.ac.th)

Received: 2 June 2017, Revised: 14 March 2018, Accepted: 5 April 2018

\begin{abstract}
The purposes of this cross-sectional descriptive study were to describe early neurological recovery in patients with acute ischemic stroke and to identify the statistical predictors of early neurological recovery at $24 \mathrm{~h}$ and 3 days after admission. A purposive random sampling was employed to recruit 220 AIS patients from 8 hospitals in the southern region of Thailand from January to May 2016, and the data was analyzed by using multivariate logistic regression analysis. The results revealed that moderate and severe stroke severity decreased neurological recovery at $24 \mathrm{~h}(\mathrm{OR}=.095, \mathrm{p}<.001$, and $\mathrm{OR}=.126, \mathrm{p}<$ .01 , respectively), compared with mild stroke severity. In addition, onset time to rt-PA within $3 \mathrm{~h}$ and 3.0 $-4.5 \mathrm{~h}$ increased the neurological recovery at $24 \mathrm{~h}(\mathrm{OR}=22.22, \mathrm{P}<.001$, and $\mathrm{OR}=17.28, \mathrm{P}<.01$, respectively), compared with those who did not receive rt-PA treatment. Lastly, age $>80$ years decreased neurological recovery at $24 \mathrm{~h}$ after admission $(\mathrm{OR}=.361, \mathrm{P}<.05)$. Neurological recovery at 3 days showed that moderate and severe stroke severity decreased neurological recovery $(\mathrm{OR}=.10, \mathrm{p}<.001$, and $\mathrm{OR}=.09, \mathrm{p}<.001$, respectively), compared with mild stroke severity. Stroke patients who had onset time to rt-PA within $3 \mathrm{~h}$ and within $3.0-4.5 \mathrm{~h}$ increased neurological recovery at 3 days $(\mathrm{OR}=16.95, \mathrm{P}<$ .05 , and $\mathrm{OR}=14.43, \mathrm{P}<.01$, respectively), compared with those who did not receive rt-PA treatment. The findings of this study show that stroke severity and onset time to rt-PA influence early neurological recovery in AIS patients.
\end{abstract}

Keywords: Early neurological recovery, acute ischemic stroke, onset time to rt-PA

\section{Introduction}

Acute ischemic stroke (AIS) is a significant cause of morbidity and mortality worldwide. Current epidemiological data indicates that 16.9 million people suffer strokes each year, which represents a global incidence of 258/100,000/year [1], and accounts for approximately 5.5 million deaths annually, with 44 million disability-adjusted life years lost. In the absence of any meaningful clinical or public health interventions, this number is expected to increase to an estimated 23 million first-ever strokes, with an associated 7.8 million deaths, by 2030 [2]. In Thailand, according to surveys conducted from 2004 to 2006, the stroke prevalence in people aged 45 - 80 years was reported as 1.9 per 1,000 people. The findings differed among 5 geographic regions of the country; including Bangkok (3.34 \%), Central Region (2.41\%), Southern Region (2.29\%), Northern Region (1.46 \%) and Northeastern Region (1.09 \%) [3].

Ischemic stroke accounts for approximately $80 \%$ of all strokes, and the goal of therapy for AIS is early neurological recovery in the brain. It has been clearly shown, however, that while the therapeutic efficacy of rt-PA in ischemic stroke persists beyond $90 \mathrm{~min}$, and possibly beyond $3 \mathrm{~h}$, its efficacy is significantly greater in the first $90 \mathrm{~min}$. The adjusted odds ratio (OR) (95\% CI) for a favorable 3-month 
http://wjst.wu.ac.th

outcome associated with rt-PA in a National Institute of Neurological Disorders and Stroke (NINDS) study is 2.11 in the 0 to $90 \mathrm{~min}$ stratum, and 1.69 in the 91 to $180 \mathrm{~min}$ stratum [4]. Patients with early neurological recovery have a lower 30-day mortality rate and are far more likely to have a favorable functional outcome [5]. Muresan et al. (2010) demonstrated that $68 \%$ of patients who show evidence of such early recovery experience a favorable 3-month outcome in comparison to $29 \%$ of those without early recovery [6].

AIS is a complex condition that requires early recognition and management by both patient and health service delivery to promote early neurological recovery. In the number-one contraindication for rt-PA administration of symptom onset $>4.5 \mathrm{~h}$, the problem of meeting time guidelines may be compounded if rt-PA is limited to urban centers. Many studies about stroke in Thailand conducted in university hospitals or at the Prasat Neurological Institute have full resources for stroke care systems. In addition, the ability to administer intravenous rt-PA at general or community hospitals involves limited resources, such as neurosurgical expertise, nurse-specialized stroke care, or stroke units. Therefore, this study aims to investigate the predictive ability of influencing factors on early recovery of patients with acute ischemic stroke in provincial or community hospitals in the first $24 \mathrm{~h}$ and at 3 days.

\section{Conceptual framework}

The theory of a behavioral model of access to health services was used as the framework for this study. The components of the framework include both patients and health services indicating the important variables of health service with impact on health outcomes. This model is composed of the following 3 interrelated concepts: 1) contextual characteristics, including 7 independent variables (distance from place of symptom attack to the hospital, level of first hospital visit, specialty of physician, years of experience of triage nurse, onset to rt-PA time, triage rating score, and compliance with clinical practice guidelines); 2) individual characteristics, including 3 independent variables (age, admission blood pressure, and stroke severity), and 3) health behaviors of patient, including one independent variable (smoking status).

\section{Materials and methods}

\section{Research design}

A cross-sectional descriptive correlation design was used to examine the effects of factors on early neurological recovery in patients with AIS, including the contextual characteristics, individual characteristics, and health behavior. The data was obtained from interviews and observational questionnaires completed by the AIS patients or witnesses and by the researcher.

\section{Population and sample}

The population in this study was AIS patients admitted to hospitals able to provide thrombolytic drugs for AIS patients.

The inclusion criteria for eligible patients were as follows:

1. Age greater than 18 years old.

2. Diagnosis by a doctor or neurologist with first-time AIS.

The exclusion criteria for ineligible patients were as follows:

1. Receipt of another diagnosis after confirming by CT scan or MRI (head injuries, tumors and/or central nervous system infections).

2. Underlying psychotic and mental disorders.

\section{Sample size and setting}

Sample size estimation was initially based on the requirements for logistic regression analysis by using the approach outlined by Hair et al. [7] who suggested that at least ten observations per estimated parameter and per category of the dependent variable were acceptable. In this study, there were 11 independent variables and 2 categories of dependent variables. Using this approach resulted in a 
http://wjst.wu.ac.th

requirement for 220 cases. The participants were recruited from hospitals in the Southern region of Thailand that were capable of providing thrombolytic drugs during January to May 2016. The inclusion criteria were as follows: age greater than 18 years old and diagnosis by a doctor or neurologist as firstever time AIS.

\section{Instruments}

The following 5 instruments were used:

Demographic characteristics questionnaire covering age, gender, education level, occupation, income, income sufficiency, welfare, mode of transportation, first hospital admission, and distance from hospital.

Clinical characteristics questionnaire covering chief complain, presenting clinical symptoms in emergency department, vital signs, stroke sub-type diagnosis, CT/ MRI and lesion site results, co-morbid diseases, and complications.

Time form record covering onset time of symptoms, time to registration in emergency department, time to start triage by a nurse, time to finish triage, time to start assessment by physician, time to lab, time to $\mathrm{CT}$, time to neurologist assessment, time to rt-PA treatment or start beginning of treatment, and discharge time from emergency department.

The National Institutes of Health Stroke Scale (NIHSS), an instrument for measuring stroke severity on admission and early neurological recovery at $24 \mathrm{~h}$ and 3 days after treatment.

The NIHSS consists of 11 items that assess the severity of impairments (loss of consciousness, ability to respond to questions and obey simple commands, deviation of gaze, hemianopsia, facial palsy, limb movements of paretic limb, limb ataxia, sensory loss, neglect, dysarthria, and aphasia). Each item is rated on a 3 - 4 point ordinal scale, with lower scores reflecting less impairment. The total score ranges from 0 (no deficit) to 42 (significant deficit). The instrument validity and reliability are at the excellent level, and administration is easy to complete within 5 - $10 \mathrm{~min}$.

Early neurological recovery was used to measure neurological improvement at $24 \mathrm{~h}$ after admission. Total scores were interpreted based on early neurological recovery, with NIHSS scores of 0 to 3 points, or a decrease of $\geq 4$ points [8].

Validity: the National Institutes of Health Stroke Scale (NIHSS) is a standard instrument that is recommended by the National Institute of Neurological Disorders and Stroke for use in stroke assessment and measurement. The NIHSS is currently used to determine treatment options, anticipate discharge planning and measure patient outcomes [9]. The content validity index (CVI) value of the National Institutes of Health Stroke Scale (NIHSS) was 1.0. The Kappa coefficient of the NIHSS was 0.87.

Clinical Practice Guideline for Acute Ischemic Stroke: the measurement of compliance with Clinical Practice Guidelines (CPG) for AIS was developed by the researcher based on the related literature, which contained 12 items for onset time $<4.5 \mathrm{~h}$ and 9 items for onset time $4.5-72 \mathrm{~h}$. The assessment comes from the obligate procedures provided in the timeline for the standard stroke CPG of collaboration from the Prasart Neurological Institute and other educational institutes, which is congruent with the Helsingborg Declaration 2006 on Stroke Strategies and Canadian Best Practice. The assessment was based on the good practice indicators for ischemic stroke by Toward Clinical Excellence' Network of Thailand. The items include stroke unit care, computed tomography scan (CT scan) or magnetic resonance imaging (MRI), blood sugar examination, diagnosis, early antiplatelet therapy (ASA), control blood pressure, control blood pressure, supplement oxygen, early stroke rehabilitation, and swallowinng test within $24 \mathrm{~h}$ or before giving any food. If the stroke service follows each item, a one-point score is given. In contrast, if the service does not follow the item, a score of zero will be given.

Total scores range from 0 to 12 for onset times $<4.5 \mathrm{~h}$ and 0 to 9 for onset times of $4.5-72 \mathrm{~h}$. Higher scores for received care service indicate higher quality of access to acute stroke care. The total score was divided into 2 levels. Scores of $10-12$ points were given for onset time $<4.5 \mathrm{~h}$ and $7-9$ points were given for onset times of 4.5 - $72 \mathrm{~h}$, which indicated CPG compliance. 
http://wjst.wu.ac.th

\section{Ethical considerations}

Ethics approval for this study was obtained from the Institutional Review Board (IRB), Faculty of Nursing, Mahidol University (Protocol ID\# NS2016/ 322.1901), Maharaj Hospital Nakhon Si Thammarat (Protocol ID\# 14/2559), and Hatyai Hospital (Protocol ID\#12/2559). All participants were informed regarding the research objectives, assurance of privacy, confidentiality, and anonymity; the subjects' right to withdraw from the study without penalty or effect on their treatment and health care services; and the usefulness of the study outcomes. Those who agreed to participate signed informed consent forms.

\section{Data collection}

The participants were selected from emergency departments and those meeting the inclusion criteria were approached. The participants or their families or witnesses who took the participants to the hospital were asked to complete demographic data forms, and some clinical data on the presenting clinical symptoms, activities done after symptom onset, time of stroke onset, and transportation to the hospital were recorded. The NIHSS was assessed based on admission for assessing stroke severity, which is categorized as mild $(0-6)$, moderate $(7-15)$, or severe $(\geq 16)$. In addition, the NIHSS was performed at $24 \mathrm{~h}$ and 3 days after treatment to assess early neurological recovery.

\section{Data analysis}

Data were doubly entered into the Statistical Package of the Social Sciences for Personal Computer (SPSS/PC+) and analyzed as follows:

1. The demographic characteristics of the samples and the variables of the study were analyzed by using frequency, percentage, mean, and standard deviation.

2. Multivariate logistic regression analysis was used to determine predictability of early neurological recovery in patients with AIS and independent variables, such as distance from place of symptom attack to hospital, level of first hospital registration, physician specialty, triage nurse experience, triage rating score, onset to rt-PA time, age, admission BP, admission stroke severity, and smoking. Statistically significant prediction of early neurological recovery was set at an interval of $95 \%$.

\section{Results and discussion}

\section{Characteristics of patients with AIS}

At total of 8 hospitals were randomly recruited into the study. Two hundred and twenty ischemic stroke patients, ranging from 26 to 28 per hospital, were recruited. The patients had a mean of age 64.35 (SD 14.08) years (range, 20 to 98 years). Most (55.9\%) were males, and the majority of the patients (99.5 $\%)$ had been diagnosed ischemic stroke in an emergency room. More than half were non-smokers, and one-third were current smokers $(32.7 \%)$. Most of the patients $(56.8 \%)$ had systolic blood pressure between 141 and $180 \mathrm{mmHg}$ (mean 166.6, SD 27.98) (Table 1), and half of the participants (51.8\%) were allocated based on mild stroke severity. 
http://wjst.wu.ac.th

Table 1 General characteristics and clinical characteristics of AIS patients.

\begin{tabular}{|c|c|c|c|c|c|c|}
\hline \multirow[t]{2}{*}{ Characteristics } & \multicolumn{2}{|c|}{$\begin{array}{c}\text { Total } \\
(\mathbf{N}=\mathbf{2 2 0})\end{array}$} & \multicolumn{2}{|c|}{$\begin{array}{c}\text { Receiving rt-PA } \\
(\mathbf{N}=29)\end{array}$} & \multicolumn{2}{|c|}{$\begin{array}{c}\text { Non receiving rt-PA } \\
(N=191)\end{array}$} \\
\hline & Number & Percent & Number & Percent & Number & Percent \\
\hline \multicolumn{7}{|l|}{ Gender } \\
\hline Male & 123 & 55.9 & 18 & 62.1 & 105 & 55.0 \\
\hline Female & 97 & 44.1 & 11 & 37.9 & 86 & 45.0 \\
\hline \multicolumn{7}{|l|}{ Age (Year) } \\
\hline$\leq 60$ & 90 & 41.0 & 15 & 57.7 & 75 & 39.2 \\
\hline $61-80$ & 103 & 46.8 & 13 & 44.8 & 90 & 47.2 \\
\hline$\geq 81$ & 27 & 12.3 & 1 & 3.4 & 26 & 13.6 \\
\hline Mean \pm SD, Range & $64.35 \pm 14.08$ & $20-98$ & $60.41 \pm 14.16$ & $32-83$ & $64.95 \pm 14.0$ & $20-98$ \\
\hline \multicolumn{7}{|l|}{ Smoking status } \\
\hline Non smokers & 119 & 54.1 & 11 & 37.9 & 108 & 56.5 \\
\hline Ex-smokers & 29 & 13.2 & 5 & 17.2 & 24 & 12.6 \\
\hline Current smokers & 72 & 32.7 & 13 & 44.8 & 59 & 30.9 \\
\hline \multicolumn{7}{|c|}{ Systolic blood pressure on admission at rt-PA hospital } \\
\hline $\mathrm{SBP} \leq 140 \mathrm{mmHg}$ & 34 & 15.5 & 7 & 24.1 & 27 & 14.1 \\
\hline SBP 141-180 mmHg. & 125 & 56.8 & 18 & 62.1 & 107 & 56.0 \\
\hline SBP181-220 mmHg. & 54 & 24.5 & 2 & 6.9 & 52 & 27.2 \\
\hline $\mathrm{SBP}>220 \mathrm{mmHg}$ & 7 & 3.2 & 2 & 6.9 & 5 & 2.6 \\
\hline Mean \pm SD, Range (min) & $166.6 \pm 27.98$ & $92-240$ & $155.2 \pm 30.85$ & $92-229$ & $168.3 \pm 27.19$ & $104-240$ \\
\hline \multicolumn{7}{|l|}{ Admission stroke severity } \\
\hline Mild (NIHSS $=0-6)$ & 114 & 51.8 & 5 & 17.2 & 109 & 57.1 \\
\hline Moderate $($ NIHSS $=7-15)$ & 85 & 38.6 & 17 & 58.6 & 68 & 35.6 \\
\hline Severe $($ NIHSS $=\geq 16)$ & 21 & 9.5 & 7 & 24.1 & 14 & 7.3 \\
\hline
\end{tabular}

Transportation and health service access of acute ischemic stroke patients are shown in Table 2. The mean distance from the place of symptom onset to a hospital capable of providing rt-PA was 24.58 kilometers (SD 22.03), with a range of $0-130 \mathrm{~km}$. Furthermore, more than half of all patients $(63.6 \%)$ had a distance of $25 \mathrm{~km}$ from hospital. Most of the patients $(96.8 \%)$ went to hospital by selftransportation. Only $0.9 \%$ of the participants used emergency medical services. Two-thirds of the participants $(65.4 \%)$ went to a hospital capable of administering intravenous rt-PA treatment, consisting of general hospitals (44.5\%) and excellent hospitals (20.9\%), while nearly $35 \%$ (34.5\%) went to health care services that were not capable of administering intravenous rt-PA, including community hospitals $(28.6 \%)$, primary care units $(3.2 \%)$ and private hospitals $(2.7 \%)$. The median onset time to hospital was $261 \mathrm{~min}$ (range, 128 - 499). Interestingly, approximately $41 \%$ of the patients gained access to hospital care within $3 \mathrm{~h}$. 
http://wjst.wu.ac.th

Table 2 Transportation and health service access of AIS patients.

\begin{tabular}{|c|c|c|c|c|c|c|}
\hline \multirow[t]{2}{*}{ Characteristics } & \multicolumn{2}{|c|}{$\begin{array}{c}\text { Total } \\
(\mathbf{N}=\mathbf{2 2 0})\end{array}$} & \multicolumn{2}{|c|}{$\begin{array}{l}\text { Receiving rt-PA } \\
(\mathbf{N}=29)\end{array}$} & \multicolumn{2}{|c|}{$\begin{array}{c}\text { Non receiving rt-PA } \\
(\mathrm{N}=191)\end{array}$} \\
\hline & Number & Percent & Number & Percent & Number & Percent \\
\hline \multicolumn{7}{|c|}{ Distance from place of symptom onset to hospital (able to provide rt-PA treatment) } \\
\hline$\leq 25$ kilometers & 140 & 63.6 & 19 & 62 & 122 & 63.9 \\
\hline 26-50 kilometers & 55 & 25.0 & 9 & 31.0 & 46 & 24.1 \\
\hline 51-80 kilometers & 20 & 9.1 & 2 & 6.9 & 18 & 9.4 \\
\hline$>80$ kilometers & 5 & 2.3 & - & & 5 & 2.6 \\
\hline Mean \pm SD, Range & $24.58 \pm 22.03$ & $0-130$ & $23.66 \pm 19.92$ & $0-78$ & $24.72 \pm 22.38$ & $1-130$ \\
\hline \multicolumn{7}{|c|}{ Transportation to first hospital } \\
\hline Self-transportation & 203 & 96.8 & 28 & 96.6 & 185 & 97.0 \\
\hline Volunteer car service & 2 & 0.9 & - & - & 2 & 1.0 \\
\hline $\begin{array}{l}\text { Local government } \\
\text { emergency service }\end{array}$ & 2 & 0.9 & - & - & 2 & 1.0 \\
\hline $\begin{array}{l}\text { Emergency medical } \\
\text { service (1669) }\end{array}$ & 2 & 0.9 & - & - & 2 & 1.0 \\
\hline Other & 1 & 0.5 & 1 & 3.4 & - & - \\
\hline \multicolumn{7}{|l|}{ First hospital visit } \\
\hline Private hospital & 6 & 2.7 & - & - & 6 & 3.1 \\
\hline Primary care unit & 7 & 3.2 & - & - & 7 & 3.7 \\
\hline Community hospital & 63 & 28.6 & 12 & 41.4 & 51 & 26.7 \\
\hline General hospital & 98 & 44.5 & 10 & 34.5 & 88 & 46.1 \\
\hline Excellent hospital & 46 & 20.9 & 7 & 24.1 & 39 & 20.4 \\
\hline
\end{tabular}

In-hospital services for acute ischemic stroke patients are shown in Table 3. The triage levels of AIS patients on presentation at the emergency department in this study were categorized as emergency, urgency, semi- urgency, non- urgency, and critical $(70.5,24.5,2.5 .1 .8$, and $0.9 \%)$, respectively. In this study, intravenous rt-PA therapy was performed in 29 cases (13.18\%). The mean onset to needle (rt-PA) time was $185.83 \mathrm{~min}$ (SD 46.51) within a range of $62-240 \mathrm{~min}$. Only 2 participants received intravenous rt-PA within $90 \mathrm{~min}$. Most of the patients $(68.7 \%)$ were compliant with clinical practice guidelines for AIS, including compliance with CPG for arrival time to hospital $>4.5 \mathrm{~h}(51.4 \%)$, and $17.31 \%$ complied with CPG for arrival time to hospital $\leq 4.5 \mathrm{~h}$.

For overall triage nurse experience, the average years of emergency nursing experience was 7.1 (SD 5.50), with a range of 1 to 30 years, and half of the triage nurses $(49.1 \%)$ had experience of less than 5 years in emergency care. The characteristics of the physicians who treated AIS patients comprised specialists in internal medicine $(68.2 \%)$, neurologists $(22.7 \%)$, general practitioners $(8.2 \%)$, and emergency physicians $(0.9 \%)$. 
http://wjst.wu.ac.th

Table 3 In-hospital care services for AIS patients.

\begin{tabular}{|c|c|c|c|c|c|c|}
\hline \multirow[t]{2}{*}{ Characteristics } & \multicolumn{2}{|c|}{$\begin{array}{c}\text { Total } \\
(\mathbf{N}=\mathbf{2 2 0})\end{array}$} & \multicolumn{2}{|c|}{$\begin{array}{l}\text { Receiving rt-PA } \\
(\mathrm{N}=29)\end{array}$} & \multicolumn{2}{|c|}{$\begin{array}{l}\text { Non receiving rt-PA } \\
(\mathrm{N}=191)\end{array}$} \\
\hline & Number & Percent & Number & Percent & Number & Percent \\
\hline \multicolumn{7}{|l|}{ Emergency triage level } \\
\hline Critical & 2 & 0.9 & 1 & 3.4 & 1 & 0.5 \\
\hline Emergency & 155 & 70.5 & 28 & 96.6 & 127 & 66.5 \\
\hline Urgency & 54 & 24.5 & - & - & 54 & 28.3 \\
\hline Semi-urgency & 5 & 1.8 & - & - & 5 & 2.6 \\
\hline Non-urgency & 4 & 0.9 & - & - & 4 & 2.1 \\
\hline \multicolumn{7}{|c|}{ Onset to needle (rt-PA) Time (n=29) } \\
\hline $0-90 \mathrm{~min}$ & & & 2 & 6.9 & & \\
\hline $91-180 \mathrm{~min}$ & & & 8 & 27.6 & & \\
\hline $181-270 \mathrm{~min}$ & & & 19 & 65.5 & & \\
\hline Mean $\pm \mathrm{SD}$, Range & & & $185.83 \pm 46.51$ & $62-240$ & & \\
\hline \multicolumn{7}{|c|}{ Compliance to CPG of stroke care } \\
\hline $\begin{array}{l}\text { Compliance with CPG for } \\
\text { arrival time to hospital } \leq 4.5 \mathrm{~h}\end{array}$ & 69 & 17.3 & 10 & 34.5 & 50 & 26.2 \\
\hline $\begin{array}{l}\text { Compliance with CPG for } \\
\text { arrival time to hospital }>4.5 \mathrm{~h}\end{array}$ & 113 & 51.4 & 19 & 65.5 & 113 & 59.2 \\
\hline Non-compliance with CPG & 38 & 31.4 & - & - & 28 & 14.7 \\
\hline \multicolumn{7}{|l|}{ Years of triage nurse experience } \\
\hline$\leq 2$ years & 19 & 8.8 & 2 & 6.9 & 17 & 8.9 \\
\hline $3-5$ years & 91 & 41.4 & 7 & 24.1 & 84 & 44.0 \\
\hline $6-10$ years & 85 & 38.6 & 14 & 48.8 & 71 & 37.2 \\
\hline $11-20$ years & 16 & 7.3 & 4 & 13.8 & 12 & 6.3 \\
\hline$>20$ years & 9 & 4.1 & 2 & 6.9 & 7 & 3.7 \\
\hline Mean \pm SD, Range & $7.10 \pm 5.50$ & $1-30$ & $8.62 \pm 6.37$ & $2-29$ & $6.83 \pm 5.35$ & $1-30$ \\
\hline \multicolumn{7}{|c|}{ Physician who treated stroke patients emergency department } \\
\hline Neurologist & 50 & 22.7 & 16 & 55.2 & 34 & 17.8 \\
\hline Internal Medicine & 150 & 68.2 & 13 & 44.8 & 137 & 71.1 \\
\hline Emergency Physician & 2 & 0.9 & - & - & 2 & 1.0 \\
\hline General Practitioner & 18 & 8.2 & - & - & 18 & 9.4 \\
\hline
\end{tabular}

Early neurological recovery of all patients with AIS at $24 \mathrm{~h}$ and 3 days was observed at 16 and $25 \%$ $(\mathrm{n}=220)$. Among the patients who received rt-PA, $89.7 \%$ were recovered at $24 \mathrm{~h}$, and $93.1 \%(\mathrm{n}=29)$ were recovered at 3 days. Of the patients who did not receive rt-PA, 8.4 and $19.9 \%(n=191)$ were recovered at $24 \mathrm{~h}$ and 3 days, respectively. 
http://wjst.wu.ac.th

Table 4 Early neurological recovery at $24 \mathrm{~h}$ and 3 days after admission.

\begin{tabular}{|c|c|c|c|c|}
\hline \multirow{2}{*}{ Early neurological recovery } & \multicolumn{2}{|c|}{$24 \mathrm{~h}$ after admission } & \multicolumn{2}{|c|}{3 days after admission } \\
\hline & Number & Percent & Number & Percent \\
\hline \multicolumn{5}{|l|}{ All participants $(n=220)$} \\
\hline Recovered & 42 & 19.1 & 55 & 25.0 \\
\hline Non recovered & 178 & 80.9 & 165 & 75.0 \\
\hline \multicolumn{5}{|c|}{ Participants who received rt-PA treatment $(n=29)$} \\
\hline Recovered & 26 & 89.7 & 27 & 93.1 \\
\hline Not recovered & 3 & 10.3 & 2 & 6.8 \\
\hline \multicolumn{5}{|c|}{ Participants who did not receive rt-PA treatment $(n=191)$} \\
\hline Recovered & 16 & 8.4 & 38 & 19.9 \\
\hline Not recovered & 175 & 91.6 & 153 & 80.1 \\
\hline
\end{tabular}

\section{Multiple logistic regression analysis}

Simple logistic regression analysis first investigated the variables for associations with neurological recovery, as well as each outcome of interest. For screening steps, variables whose respective associations had $p$-value $\leq 0.15$ were considered as potential factors. The results revealed that 4 variables had $p$-value $<0.15$; admission stroke severity $(\mathrm{p}$-value $=.000)$, onset to rt-PA time ( $\mathrm{p}$-value $=.003)$, age $(\mathrm{p}$-value $=$ $.005)$, and physician specialty (p-value $=.069$ ) (Table 4). This was followed by analyzed by multiple logistic regression analysis.

The 4 variables (admission stroke severity, onset to rt-PA time, age, and specialty of physician) had potential for multiple logistic regression analysis. Values of 1, 2, 3, and 4 factors were added into the model, respectively. Next, the dichotomous logit model gave a better fit due to Akaike's Information Criterion (AIC) and Likelihood ratio estimates compared to those of the proportional odds model. The best model is the one with minimum Likelihood and ratio AIC value.

The best model of related factors associated with early neurological recovery at $24 \mathrm{~h}$ after admission in AIS patients revealed that moderate and severe stroke severity decreased neurological recovery at $24 \mathrm{~h}$ $(\mathrm{OR}=.095,95 \% \mathrm{CI}: .044-.205, \mathrm{p}<.001$, and $\mathrm{OR}=.126,95 \% \mathrm{CI}: .034-.465, \mathrm{p}<.01$, respectively $)$, compared with mild stroke severity. Onset time to rt-PA within $3 \mathrm{~h}$ and $3.0-4.5 \mathrm{~h}$ increased neurological recovery at $24 \mathrm{~h}(\mathrm{OR}=22.22,95 \% \mathrm{CI}: 5.454-90.527, \mathrm{P}<.001$, and $\mathrm{OR}=17.28,95 \% \mathrm{CI}: 3.079$ 97.001, $\mathrm{P}<.01$, respectively), compared with those who did not receive rt-PA treatment. Lastly, age $>80$ years decreased neurological recovery at $24 \mathrm{~h}$ after admission $(\mathrm{OR}=.361,95 \% \mathrm{CI}: .120-1.085 \mathrm{P}<.05)$.

For neurological recovery at 3 days, the findings showed that moderate and severe stroke severity decreased neurological recovery $(\mathrm{OR}=.10, \mathrm{p}<.001$, and $\mathrm{OR}=.09, \mathrm{p}<.001$, respectively), compared with mild stroke severity. The stroke patients who had onset time to rt-PA within $3 \mathrm{~h}$ and within $3.0-4.5$ $\mathrm{h}$ increased neurological recovery at 3 days $(\mathrm{OR}=16.95, \mathrm{P}<.05$, and $\mathrm{OR}=14.43, \mathrm{P}<.01$, respectively), compared with those who did not receive rt-PA treatment. The details of the binary logistic regression are presented in Table 5. 
http://wjst.wu.ac.th

Table 5 Logistic regression of factors associated with early neurological recovery at $24 \mathrm{~h}$ and 3 days after admission $(\mathrm{n}=220)$.

\begin{tabular}{|c|c|c|c|c|c|}
\hline Variable & $\beta$ & Wald & Odd ratio & $95 \%$ CI & P-value \\
\hline \multirow{2}{*}{\multicolumn{6}{|c|}{$\begin{array}{l}\text { Neurological recovery at } 24 \mathrm{~h} \\
\text { Stroke Severity }\end{array}$}} \\
\hline & & & & & \\
\hline \multicolumn{6}{|l|}{ Stroke severity (mild) } \\
\hline Stroke severity (moderate) & -2.355 & 35.751 & .095 & $.044-.205$ & .000 \\
\hline Stroke severity (severe) & -2.068 & 9.702 & .126 & $.034-.465$ & .002 \\
\hline \multicolumn{6}{|l|}{ Onset time to rt-PA } \\
\hline \multicolumn{6}{|l|}{ No rt-PA received } \\
\hline $\begin{array}{l}\text { Onset time to rt-PA } \\
\text { (within } 3 \mathrm{~h} \text { ) }\end{array}$ & 3.101 & 18.723 & 22.220 & $5.454-90.527$ & .000 \\
\hline $\begin{array}{l}\text { Onset time to rt-PA } \\
(3.0-4.5 \mathrm{~h})\end{array}$ & 2.850 & 10.483 & 17.282 & $3.079-97.001$ & .001 \\
\hline \multicolumn{6}{|l|}{ Age } \\
\hline \multicolumn{6}{|l|}{ Age (<60 years) } \\
\hline Age (60-80 years) & -.582 & 2.829 & .559 & $.283-1.101$ & .093 \\
\hline Age ( $>80$ years) & -1.019 & 3.295 & .361 & $.120-1.085$ & .049 \\
\hline \multicolumn{6}{|l|}{ Neurological recovery at 3 days } \\
\hline \multicolumn{6}{|l|}{ Stroke severity } \\
\hline \multicolumn{6}{|l|}{ Stroke severity (mild) } \\
\hline Stroke severity (moderate) & -2.283 & 39.134 & .102 & $.050-.209$ & .000 \\
\hline Stroke severity (severe) & -2.377 & 14.782 & .093 & $.028-.312$ & .000 \\
\hline \multicolumn{6}{|l|}{ Onset time to rt-PA } \\
\hline No rt-PA received & & & & & \\
\hline $\begin{array}{l}\text { Onset time to rt-PA } \\
\text { (within } 3 \mathrm{~h} \text { ) }\end{array}$ & 2.830 & 6.546 & 16.951 & $1.939-148.185$ & 011 \\
\hline $\begin{array}{l}\text { Onset time to rt-PA } \\
(3.0-4.5 \mathrm{~h})\end{array}$ & 2.669 & 11.181 & 14.429 & $3.018-68.982$ & .001 \\
\hline
\end{tabular}

\section{Discussion}

Stroke severity was the main factor influencing early neurological recovery. In this study, the participants had different stroke severity levels, from mild $(51.8 \%)$ to moderate $(38.6 \%)$ and severe $(9.5$ $\%$ ) at admission, which might have resulted in different outcomes at $24 \mathrm{~h}$ and 3 days after admission. Similar findings have reported that the NIHSS score at admission was strongly associated with outcomes of acute hospitalization after multivariate adjustment [10]. Consistently, other studies have found initial severity ratings to be strongly related to final hospital discharge disposition, length of stay, and hospital charges (all $\mathrm{p}$ values $<.001$ ). Ninety percent of patients with mild strokes were ultimately discharged, whereas only one-third of patients with severe strokes improved enough to go home from an acute hospital setting [11].

Moreover, this finding demonstrates that onset time to rt-PA is a great predictor of early neurological recovery. These findings confirm and extend data regarding the relation between onset to treatment time and good functional outcomes from formal clinical trials. The most recent analysis of pooled data from completed trials of IV rt-PA showed that earlier treatment is associated with a greater magnitude of benefit [12]. Congruently, another previous study found that every 10 min delay in the start of thrombolytic infusion within the $1-3 \mathrm{~h}$ treatment time in 100 patients treated with IV therapy resulted in 0.9 fewer patients with improved final disability outcome [13]. The National Institutes of Neurological Disorders and Stroke (NINDS) rt-PA stroke study reported that patients treated with rt-PA within $0-90$ 
http://wjst.wu.ac.th

min after stroke onset showed an increased likelihood of improvement at $24 \mathrm{~h}$ and a favorable 3 month outcome, compared to patients treated at $>90 \mathrm{~min}$ [3].

In addition, this result showed that age $>80$ years decreased neurological recovery at $24 \mathrm{~h}$ after admission by $.361(95 \% \mathrm{CI}=.120-1.085, \mathrm{P}<.05)$, compared with ages younger than 60 years. This finding was similar to that of a study by Tseng and Chang [10] showing that every increase of one year in age decreased the odds for excellent outcome at discharge by approximately 5 percent $(p=0.002)$. Another previous study indicated that relative improvement decreased with increasing age. In other words, patients younger than 55 years showed an improvement of $67 \%$ of the maximum possible improvement, compared to only 50 percent of patients above 55 years (adjusted $\mathrm{R}^{2}=0.120$, $\beta$ age $=$ $0.130, \mathrm{p}<0.001)$ [14]. However, in an earlier study investigating patients aged 80 years, the rate of neurological improvement in those receiving thrombolytic treatment was higher than the rate in those patients not receiving thrombolytic treatment (58.8 vs. $14.1 \%, \mathrm{p}<0.01)$. It was concluded, therefore, that thrombolysis increases the rate of neurological improvement in patients aged 80 years [15].

Lastly, physician specialty did not show predictive ability in this study. The current data support multiple approaches to obtaining specialist consultation when needed in the setting of acute stroke. These range from using committed local physicians to using telephones or smart phones to access local or regional specialists or to activate an acute stroke team. The development of local stroke processes to maximize available local and regional resources and to clearly identify access to neurological expertise optimizes opportunities for acute treatment [16].

\section{Conclusions}

The findings suggest that stroke severity and onset time to rt-PA are important factors influencing early neurological recovery at both $24 \mathrm{~h}$ and 3 days after admission. In addition, age $>80$ years decreased neurological recovery at $24 \mathrm{~h}$ after admission, compared with patients younger than 60 years of age.

\section{Limitations of the study}

1. The cut-off score of the NIHSS effect on outcome are demonstrated by the trials of thrombolytic therapy. This study categorized the NIHSS as mild $(0-6)$, moderate $(7-15)$, or severe $(\geq 16)$ (Tseng and Chang [10]). However, the NIHSS can be divided into other categories, such as minor stroke $(0-4)$, moderate stroke (5 - 15), moderate to severe stroke (16 - 20), and severe stroke $(21-42)$. The differences in the NIHSS categories might have influenced recovery outcome in this study.

2. At 3 days, an outcome might not have been adequate for assessment of the residual dependency of patients who survived, because more time is likely to be needed for full functional recovery. However, according to a previous analysis of the data from stroke clinical trials, global disability status at 3 days can be a reliable proxy of 3-month disability outcomes.

\section{Acknowledgements}

The researcher would like to express the deepest appreciation and thanks to the patients with acute ischemic stroke who participated in this study by sacrificing their time to contribute and share their experiences.

\section{References}

[1] AG Thrift, DA Cadilhac, T Thayabaranathan, G Howard, VJ Howard, PM Rothwell, VL Feigin, B Norrving, GA Donnan and DA Cadilhac. Global stroke statistics. Int. J. Stroke 2014; 9, 870-947.

[2] K Strong, C Mathers and R Bonita. Preventing stroke: Saving lives around the world. Lancet Neurol. 2007; 6, 182-7.

[3] S Hanchaiphiboolkul, N Poungvarin, S Nidhinandana, N Suwanwela, P Puthkhao, S Towanabut, T Tantirittisak, J Suwantamee and M Samsen. Prevalence of stroke and stroke risk factors in Thailand: Thai Epidemiologic Stroke (TES) study. J. Med. Assoc. Thai. 2011; 94, 427-36. 
http://wjst.wu.ac.th

[4] JR Marler, BC Tilley, M Lu, TG Brott, PC Lyden, JC Grottaet, JP Broderick, SR Levine, MP Frankel, SH Horowitz, ECJ Haley, CA Lewandowski and TP Kwiatkowski. Early stroke treatment associated with better outcome: The NINDS rt-PA stroke study. Neurology 2000; 55, 1649-55.

[5] O Khiaocharoen, S Pannarunothai, W Riewpaiboon, L Ingsrisawang and Y Teerawattananon. Economic evaluation of rehabilitation services for inpatients with stroke in Thailand: A prospective cohort study. Value Health Reg. Issues 2012; 1, 29-35.

[6] IP Muresan, P Favrole, P Levy, F Andreux, B Marro and S Alamowitch. Very early neurologic improvement after intravenous thrombolysis. Arch. Neurol. 2010; 67, 1323-8.

[7] JF Hair, WC Black, BJ Babin and RE Anderson. Multivariate Data Analysis. Pearson Education, New Jersey, 2010.

[8] M Mazighi, H Meseguer, J Labreuche, JM Serfaty, JP Laissy, PC Lavallee, L Cabrejo, C Guidoux, B Lapergue, IF Klein, JM Olivot, A Rouchaud, JP Desilles, E Schouman-Claeys and P Amarenco. Dramatic recovery in acute ischemic stroke is associated with arterial recanalization grade and speed. Stroke 2012; 43, 2998-3002.

[9] C Weimar, C Weber, M Wagner, O Busse, RL Haberl, KW Lauterbach and HC Diener. Management patterns and health care use after intracerebral hemorrhage: A cost-of-illness study from a societal perspective in Germany. Cerebro. Dis. 2003; 15, 29-36.

[10] MC Tseng and KC Chang. Stroke severity and early recovery after first-ever ischemic stroke: Results of a hospital-based study in Taiwan. Health Pol. 2006; 79, 73-8.

[11] PS Reynolds, CT Crenshaw, DS Lefkowitz, BJ Shelton, JS Preisser and CH Tegeler. A practical stroke severity scale predicts hospital outcomes. J. Stroke Cerebro. Dis. 2001; 10, 231-5.

[12] KR Lees, E Bluhmki, R Kummer, TG Brott, D Toni, JC Grotta, GW Albers, M Kaste, JR Marler, SA Hamilton, BC Tilley, SM Davis, GA Donnan, W Hacke, K Allen, J Mau, D Meier, GD Zoppo, DAD Silva, KS Butcher, MW Parsons, PA Barber, C Levi, C Bladin and G Byrnes. Time to treatment with intravenous alteplase and outcome in stroke: An updated pooled analysis of ECASS, ATLANTIS, NINDS, and EPITHET trials. Lancet 2010; 375, 1695-703.

[13] MG Lansberg, M Schrooten, E Bluhmki, VN Thijs and JL Saver. Treatment time-specific number needed to treat estimates for tissue plasminogen activator therapy in acute stroke based on shifts over the entire range of the modified Rankin Scale. Stroke 2009; 40, 2079-84.

[14] C Kugler, T Altenhoner, P Lochner and A Ferbert. Does age influence early recovery from ischemic stroke? A study from the Hessian Stroke Data Bank. J. Neurol. 2003; 250, 676-81.

[15] CT Ong, SF Sung, CS Wu, YC Hsu, YH Su, CH Li and LC Hung. Early neurological improvement after intravenous tissue plasminogen activator infusion in patients with ischemic stroke aged 80 years or older. J. Chin. Med. Assoc. 2014; 77, 179-83.

[16] EC Jauch, JL Saver, HP Adams, A Bruno, JJ Connors, BM Demaerschalk, P Khatri, PWJ McMullan, AI Qureshi, K Rosenfield, PA Scott, DR Summers, DZ Wang, M Wintermark and H Yonas. Guidelines for the early management of patients with acute ischemic stroke: A guideline for healthcare professionals from the American Heart Association/American Stroke Association. Stroke 2013; 44, 870-947. 